\title{
El capital como sujeto y el carácter idealista de la dialéctica hegeliana
}

\author{
Capital as a subject and the idealistic character of the Hegelian dialectic
}

\author{
Rodrigo Steimberg*
}

Resumen: El presente escrito toma por objeto la lectura que realiza Riccardo Bellofiore del vínculo entre Marx y Hegel. Bellofiore sostiene que el idealismo de Hegel responde a que expresa el movimiento real del capital, atribuyéndole a la dialéctica de lo absoluto una circularidad de la que el capital carece, ya que para alcanzar esta condición debe doblegar la resistencia de la clase obrera. Frente a la propuesta de Bellofiore, nuestra tesis es que Hegel se representa la autonomización del capital como si fuese la del pensamiento respecto de sus determinaciones sociales.

Palabras clave: Dialéctica, Capital, Hegel, Bellofiore, Sujeto, Idealismo

\begin{abstract}
The present paper takes as its object the reading that Riccardo Bellofiore makes of the link between Marx and Hegel. Bellofiore argues that Hegel's idealism is due to expressing the real movement of capital, but attributing to the dialectic of the Absolute a circularity that capital lacks, since to achieve this condition it must overcome the resistance of the working class. In contrast to Bellofiore's proposal, our thesis is that Hegel represents the autonomization of capital as a subject as if it were that of thought of its social determinations.
\end{abstract}

Key words: Dialectics, Capital, Hegel, Bellofiore, Subject, Idealism

Recibido: 5 enero 2019 Aceptado: 2 abril 2019

\section{Introducción}

La cuestión del vínculo entre Marx y Hegel ha sido objeto de debate en el campo marxista desde sus inicios. Recientemente, y de la mano de un conjunto de pensadores que han puesto el foco en el aspecto metodológico de la crítica de la economía política desarrollada por Marx ${ }^{1}$, este tópico ha recobrado vitalidad como objeto de discusión. El presente trabajo pretende insertarse en este campo general de

\footnotetext{
* Argentino, Doctor en Ciencias Sociales por la Facultad de Ciencias Sociales de la Universidad de Buenos Aires. Actualmente, se desempeña como Becario Posdoctoral por el Consejo Nacional de Investigaciones Científicas y Técnicas, con sede en la Universidad Nacional de Quilmes.

${ }^{1}$ Smith, Tony. The Logic of Marx's Capital. Replies to hegelian criticisms, Albany, SUNY press, 1990; Moseley, Fred y Cambell, Martha, eds. New Investigations of Marx's Method. New Jersey, Humanities Press International, 1997; Arthur, Christopher. The New Dialectic and Marx's 'Capital', Leiden, Brill, 2004; Albritton, Robert y Simoulidis, John, eds. New Dialectics and Political Economy. Basingstoke, Palgrave Macmillan, 2003; Robles Báez, Mario. Dialéctica y Capital. Elementos para una reconstrucción de la crítica de la economía politica. México, Universidad Autónoma Metropolitana, 2005; Moseley, Fred y Smith, Tony, eds. Marx's Capital and Hegel's Logic. A Reexamination. Leiden, Brill, 2014.
} 
estudios, contribuyendo al esclarecimiento del vínculo entre la cuestión del capital como sujeto de la vida social bajo el modo de producción capitalista y la del vínculo de Marx con Hegel. A estos fines, nos detendremos en el trabajo de Riccardo Bellofiore, quien constituye uno de los autores enmarcados en la Dialéctica Sistemática (DS de aquí en adelante)

Nos interesa enfocar nuestro trabajo en Bellofiore porque resulta un exponente de aquellos que sostienen que el carácter idealista de la dialéctica hegeliana se debe a que refleja la inversión propia del capital, hipostasiando de este modo su condición de sujeto de la vida social. Bellofiore afirma que el capital es un sujeto que debe demostrar esta condición venciendo la resistencia de la clase trabajadora, lo cual no necesariamente consigue. Por lo tanto, la dialéctica hegeliana, como expresa conceptualmente un movimiento que es capaz de poner sus propias condiciones -la Idea- hipostasia un despliegue que en la realidad no consigue autofundarse, el capital. De ahí que no haga justicia al modo en el que opera realmente este sujeto enajenado, que en tren de postular sus presupuestos debe vencer a un sujeto-otro que es capaz de frenar su movimiento, la clase trabajadora.

Frente a esta tesis, sostendremos que el carácter idealista de la dialéctica hegeliana no se debe a que supone un movimiento circular que el capital no alcanza a lograr. Afirmaremos que dicho carácter responde a que Hegel autonomiza al pensamiento de sus determinaciones materiales, lo cual lo lleva a atribuirle a la conciencia la capacidad de ponerse en marcha por sí misma. Así, Hegel expresa filosóficamente la autonomización de la organización del trabajo social propia del capital, tomándola de forma idealista como la autonomización de la conciencia de sus determinaciones materiales.

Para desplegar nuestra hipótesis, el escrito constará de tres secciones fundamentales. En la primera de ellas, recuperaremos los aportes sustanciales de la DS respecto de la relación Marx-Hegel, a los fines de situar la perspectiva de Bellofiore. Una vez esto realizado, pasaremos a exponer el argumento específico de este autor sobre el vínculo Marx-Hegel, deteniéndonos en su explicación del carácter idealista de la filosofía hegeliana. Tras acompañar esta explicación, señalaremos los puntos que encontramos problemáticos, para pasar finalmente al desarrollo de nuestra perspectiva.

\section{La Dialéctica Sistemática y el vínculo entre Hegel y Marx}

Los autores enmarcados en el enfoque conocido como DS2 tienen en la Neue Marx-Lektüre sus antecedentes principales, corriente cuyo núcleo fueron los aportes de Helmut Reichelt y de Hans-Georg Backhaus, realizados a mediados de la década del sesenta en Alemania Occidental. La Neue Marx-Lektüre, a su vez, se apoya en la interpretación de la teoría del valor llevada a cabo por Rubin, que tiene a la formavalor como su llave maestra ${ }^{3}$.

Metodológicamente, la $D S$ es una perspectiva que acentúa el desenvolvimiento dialéctico de las categorías de la crítica marxiana de la economía política, enfatizando su relación con la Ciencia de la Lógica de Hegel, aspecto que suscitará nuestro análisis.

Dentro de la DS, Patrick Murray sostiene que la lógica de la esencia hegeliana, que se basa en mostrar que aquella aparece de un modo que se distingue de sí misma, se encuentra presupuesta en la teoría del valor de Marx, lo cual la diferencia de la de Ricardo ${ }^{4}$. En este caso, se trata del valor como esencia, cuya forma es el valor de cambio consagrado en el dinero. Éste, en la circulación de mercancías, se presenta

\footnotetext{
2 Robles Báez, op cit., 14.

3 Starosta, Guido. "Fetichismo y revolución en la teoría marxista contemporánea: una evaluación crítica de la Neue Marx-Lektüre y el Marxismo Abierto en clave metodológica”, Izquierdas, 37 (diciembre), 2017, 162-190. p. 63

${ }^{4}$ Murray, Patrick. "La necesidad del dinero: cómo Hegel ayudó a Marx a superar la teoría del valor de Ricardo". Robles Báez, Mario, comp. Dialéctica y Capital. Elementos para una reconstrucción de la crítica de la economía política, México, Universidad Autónoma Metropolitana Báez, 2005, 37-62.
} 
como el opuesto del cúmulo de valores de uso que lo determinan'. Escribe Murray: "money's retroversion from the particular use-values (commodity circulation) ends in self-annihilation rather than self-immortalization. To achieve immortality, money must be transformed into capital" 6 . El dinero, para conservarse y permanecer como dinero, debe apartarse del ámbito de la circulación, debe trascender al mundo de las mercancías. Por el contrario, en el capital, la esencia reflejada en el dinero permanece como tal al estar en movimiento, atravesando de forma inmanente el mundo de los valores de uso sin perder su identidad como valor. El capital es así valor en proceso, que toma la forma de mercancía para volver a adoptar la de dinero, como ropajes que pone y en los que no se pierde. Es decir, es valor en movimiento, valor que pare valor. Aunque se manifieste como algo distinto de sí mismo y presuponga de este modo la lógica hegeliana de la esencia, su circulación como sujeto se ajusta a la lógica del concepto ${ }^{7}$. Razón por la cual la lógica del concepto propuesta por Hegel constituye, según Murray, un punto crucial para pensar la especificidad de Marx respecto de Ricardo, que se sintetiza en la dialéctica de la forma valor ${ }^{8}$.

Tony Smith, parte de la DS pero con una posición distinta de la de Murray, rechaza que la filosofía de Hegel encierre un carácter idealista. La tarea de la filosofía, de acuerdo a su perspectiva, consiste en apropiarse de las categorías que utilizamos acríticamente en nuestra experiencia. Hegel, como expresión más acabada de esta empresa, despliega las categorías involucradas en el conocimiento del mundo y desarrolla dialécticamente su trabazón interna, que las impulsa a alcanzar mayores niveles de complejidad y concreción. Dice Smith: "What is of interest to the philosopher is the fact that it is impossible to engage in discourse without employing categories, whether our discourse concerns metaphysics, the empirical sciences, religion, or events in the everyday world. The philosophical appropriation of immediately given experience is an appropriation of categories" .

La filosofía de Hegel no sería idealista por reducir del mundo material a categorías del pensamiento. Tampoco afirmaría que la dialéctica de las categorías es idéntica a la que opera en la totalidad de lo real, sino que, nuevamente, se limitaría a reconstruir sus determinaciones fundamentales ${ }^{10}$. Es decir, Hegel no haría del mundo material la reproducción idéntica del ideal, ni buscaría reducir el primero al segundo. Justamente por esto, Smith sostiene que Marx toma de Hegel la dialéctica. Se trata de la propuesta filosófica que sostiene el método marxiano, toda vez que Marx mismo, según Smith, procede tomando a ciertas categorías, las más abstractas, como aquellas que por su propio desenvolvimiento permiten pensar la concreción y complejidad de lo real. Otro modo de decir que Marx toma de Hegel la necesidad de poner la mediación de todo fenómeno por su estructura esencial. Es decir, que Marx toma a toda determinación como una forma desplegada de su estructura interna, comprensible solamente si se la conceptualiza mediada por las categorías más generales. Dice Smith: "To put the point as provocatively as possible: the Marxist approach to political economy is correct became Hegel's theory of the syllogism is correct." ${ }^{11} \mathrm{El}$ énfasis en las relaciones y en la necesidad de un ordenamiento categorial de los fenómenos emparentaría, así, al método de Marx con el de Hegel.

Los desarrollos de Thomas Sekine y de Christopher Arthur -que es una de las figuras eminentes de la DS y a nuestro modo de ver el fundamento de Bellofiore en lo que hace a nuestro trabajo- respecto del vínculo entre Marx y Hegel presentan ciertas similitudes.

\footnotetext{
${ }_{5}^{5}$ Murray, Patrick. Marx's Theory of Scientific Knowledge. New York, Humanity Books, 1990, 191.

${ }^{6} \mathrm{Idem}$

7 Murray, op cit., 2005, 169.

8 Murray, op cit., 2005, 143 y ss.

${ }_{9}$ Murray, op cit., 1990, 15

10 Idem.

${ }^{11}$ Smith, op cit., 14.
} 
Sekine sostiene que la dialéctica del capital es idéntica a la del Absoluto hegeliano. Esta dialéctica rige al capital toda vez que consigue superar la contradicción entre valor y valor de uso ${ }^{12}$. Es decir, es la que mueve al capital una vez que este, como forma, se apropia de la riqueza material necesaria para reproducir la vida humana. Sin embargo, Sekine diferencia la dialéctica del capital de aquella entre el ser y la nada, propia del sistema hegeliano. Dice:

But a fundamental difference seems to me to exist between 'use-value' and 'naught'. Although from the point of view of the materialist dialectic, value representing capital, its subject, prevails over use-value in order to synthesize capitalism, the real implication is that this can be done only in so far as the use-value side permits it. For capitalism is historically transient. This means that the real winner in the end is usevalue (concrete wealth for human beings), which will remain even after the death of value (abstract wealth sought by capital). This is different from the implication of Hegel's dialectic of the Absolute. ${ }^{13}$

En tanto la nada es pasiva, queda definitivamente superada por el ser sin ofrecerle resistencia a su progreso dialéctico. En cambio, el "espacio" del valor de uso persiste más allá del capitalismo ya que se trata de la riqueza material, asuma o no la forma mercantil. Esta condición puede amenazar la reproducción del capitalismo, ya que es potencialmente exterior a él. Es decir, como el capitalismo es una forma transitoria de producir la riqueza social, la dialéctica que lo preside caerá una vez que el "espacio" del valor de uso adopte otra organización social. Por el contrario, el Absoluto hegeliano no tiene exterior, no hay ninguna determinación que no pueda incorporar a su dialéctica.

Christopher Arthur analiza el vínculo entre Marx y Hegel de modo similar ${ }^{14}$. Explica que el valor es un atributo que se pone de manifiesto en el intercambio. Recuperando ciertos aspectos de la argumentación de Hegel, destaca que éste, como esencia, no existe sino cuando consigue manifestarse en su apariencia, esto es, al encontrar una mercancía en cuyo cuerpo poder actualizase ${ }^{15}$. En el dinero, entonces, las mercancías se desdoblan en una cosa que les es exterior y, entonces, tienen frente a sí a su cambiabilidad universal, lo cual les permite manifestarse como esencia. Escribe Arthur "Como el equivalente inmediato de todas las mercancías, el dinero resuelve el problema cualitativo del valor a través de su idealidad pura, creando un espacio virtual -la dimensión del valor"16.

Como representante general de la riqueza, el dinero es, de este modo, una abstracción que hace de las mercancías concretas simples ejemplares suyos, especies en las que el valor se realiza. Por eso, para Arthur, el dinero es la primera figura en la que existe la abstracción real en la que consiste el mundo gobernado por las mercancías, aquella en la cual lo concreto-sensible es un soporte que toma lo abstractouniversal.

Con el capital, esta determinación se enriquece. En el ciclo D-M-D’ el valor no solo existe para sí, como su propio objeto, sino como su propio resultado, como una multiplicación producto de su propia obra. Así como en el dinero el valor existía para sí mismo, desprendiéndose de las circunstancias específicas

\footnotetext{
${ }^{12}$ Sekine, Thomas. "The Dialectic, or Logic that Coincides with Economics". Albritton, Robert y Simoulidis, John, eds. New Dialectics and Political Economy. Hampshire, Palgrave Macmillan, 2003, 120-130, p. 126.

13 Idem.

14 Vale aclarar que el propio Arthur se encarga de señalar las diferencias de su planteo con el de Thomas Sekine. Reponerlas no hace al objeto de nuestro escrito, que es señalar cómo una forma de abordar la relación de Marx con Hegel, incluso con sus matices, pone el acento en el carácter idealista de la dialéctica en un lugar erróneo, ya que implica no tomar al capital como un sujeto en sentido pleno.

15 Arthur, Christopher. "De la crítica de Hegel a la crítica de capital". Robles Báez, Mario, comp. Dialéctica y Capital. Elementos para una reconstrucción de la crítica de la economía política, México, Universidad Autónoma Metropolitana, 2005, 229-256, p. 236; Arthur, Arthur, Cristopher. 'Hegel's Logic and Marx's Capital', Moseley, Fred, ed. Marx's method in Capital. New Jersey, Humanities Press, 1993, 63-87, p. 157.

16 Arthur, op cit., 1993, 159.
} 
del intercambio, en el capital este valor para sí, según Arthur, se produce a sí mismo. Con el capital, el valor como forma separada alcanza su determinación más plena.

Para Arthur, en la exposición que realiza Marx en El Capital, con la fórmula general del capital ${ }^{17}$, se ha desatendido el valor de uso, se lo ha negado para ver la forma común a la mercancía en tanto producto intercambiable. Sin embargo, es en la esfera del valor de uso, dice, que el capital se hace "un poder real en el mundo"18. Pero en ella, el capital enfrenta a su negación: el trabajo. Así, el capital, para devenir sujeto absoluto debe negar esta negación para subsumir al trabajo en su propio movimiento, condición de lo cual es vencer a la clase trabajadora en la lucha de clases para extraerle su tiempo de trabajo ${ }^{19}$. Por lo tanto, para Arthur el capital es un proto-sujeto, que para mostrarse como tal debe producir sus propias condiciones de existencia ${ }^{20}$. En este tránsito, debe lidiar con un sujeto que a la vez es puesto por él mismo: el proletariado. Este otro interno, cuya fuerza el capital debe doblegar, convirtiéndolo en un mero accesorio, "cosificando su actividad, expropiando su producto y colonizando su conciencia" 21 , tiene la capacidad potencial de revolucionarlo. Por lo cual, para probarse como realidad absoluta, debe subordinar la realidad material del trabajo, produciéndola como su propio presupuesto. Recién allí el capital deviene realmente lo que era como forma en su figura general ${ }^{22}$. Aquí es donde Arthur introduce el paralelismo entre el capital y la Idea hegeliana. Ambos deben sumergirse en el mundo de la otredad para comprobar que son sujetos en el sentido pleno; uno frente al trabajo vivo, el otro frente a la Naturaleza. Así como el capital debe subordinar el mundo de la producción, en el que debe probarse como sujeto absoluto apropiándose del trabajo del proletariado, requisito de lo cual es doblegarlo en la lucha de clases, así el Concepto debe separarse de sí en la Naturaleza, para conformarla a su imagen y semejanza ${ }^{23}$.

Pero aquí es donde Arthur funda, también, la diferencia entre la dialéctica materialista y la hegeliana. Mientras que la Idea detenta la capacidad para subsistir en sí, para fundarse, el capital puede no hacerlo. Escribe Arthur: "Desdichadamente para el capital, no puede actualizarse a sí mismo y conquistar todas sus presuposiciones de existencia tan fácilmente como la Idea hegeliana supone. La verdadera realidad es material" 24 . Con lo cual, mientras que la Idea es capaz de manifestarse en la Naturaleza, penetrando en ella y retornando a su seno, el capital debe, para eso, derrotar a la clase obrera para ponerla como su propio presupuesto, mediando este proceso la lucha de clases. Como dijimos, Arthur constituye la apoyatura fundamental, en este aspecto, del trabajo de Bellofiore. Avancemos hacia la exposición del planteo de este último, que recuperará buena parte de las dificultades que presenta el de Arthur.

\section{Bellofiore: el capital como sujeto y la diferencia entre Marx y Hegel}

Bellofiore recupera de la exposición de Arthur que la ontología hegeliana, por idealista, reproduce lo propio del movimiento del capital: la abstracción real que lo constituye. Así como la Idea hegeliana consiste en la conversión del pensamiento en un sujeto autonomizado, así el capital en tanto valor que se valoriza se separa de las condiciones que lo produjeron. Por lo tanto, la lógica de Hegel reproduce el movimiento del capital, no a pesar de su carácter idealista sino por él. Sintetiza Bellofiore: "The isomorphism between Hegel's logic and the actuality of capital is valid, and - Arthur concludes- the

\footnotetext{
17 Marx, Karl. El capital, Tomo I, vol. 1, México, Siglo XXI Editores, 1999, 179-190.

18 Arthur, op cit., 2005, 245.

19 Ibid., 252

20 Ibid., 251.

21 Idem.

22 Arthur, op cit., 1993, 162; Arthur, op cit., 2004, 10-11 y 52-53.

23 Arthur, op cit., 2005, 255.

24 Arthur, op cit., 1993, 164.
} 
homology with the Idea is precisely a reason for criticizing it as an inverted reality where self-moving abstractions have the upper hand over human beings." 25

La matriz de las argumentaciones de Arthur y del propio Bellofiore, como él mismo lo reconoce, es el desarrollo de fines de los años sesenta y principios de los setenta realizado por Lucio Colletti ${ }^{26}$. Colletti afirma que la relación social general, el valor, se independiza de los individuos que pasan a ser sus portadores y mediadores. De este modo, el valor que se valoriza se constituye como un poder exterior que domina a los individuos y existe a través de la circulación de las mercancías que lo expresan. Escribe Bellofiore: "The 'abstract universal', which ought to be the property of the concrete, becomes a selfsubsisting entity and an active subject, with the concrete and sensuous counting only as the form of manifestation of the abstract-universal -the predicate of its own substantialised predicate. For Colletti Hegel's dialectical logic is nothing but the 'peculiar method for the peculiar object', precisely due to bis absolute idealism." 27

La lógica dialéctica de Hegel, así, reproduce la inversión propia de la sociedad que intenta conocer, siendo por lo tanto su reflejo fiel. Por eso Escribe Colletti: "la conversión del hecho en axioma metafísico, es decir, en receptáculo de lo Absoluto, antes que una operación de la filosofía hegeliana es una operación objetiva y real que realiza la sociedad misma" 28 . En esa misma medida, como dijimos, la lógica hegeliana reproduce objetivamente el movimiento propio del capital en tanto sujeto enajenado de la sociedad capitalista.

Bellofiore da cuenta del proceso mediante el cual el valor se transforma en la relación social general autonomizada, cuya especificidad consiste en tener por objeto, no la producción de valores de uso para la reproducción de la vida humana, sino más de sí misma, es decir, capital ${ }^{29}$. Relación que, aclara junto a Taylor, al reproducirse hace otro tanto con las clases sociales y la relación de explotación que las constituye. ${ }^{30}$

Para Bellofiore, el capital tiene por condición absorber la capacidad de trabajo portada en el cuerpo de la clase obrera ${ }^{31}$. En este punto, la lucha de clases se levanta como un momento que el capital debe sobrellevar exitosamente para absorber la fuerza de trabajo, incorporándola a su propia materialidad. La clase obrera, en tanto otro-interno (término que Bellofiore recupera de Arthur), debe convertirse en un apéndice del capital; en caso de resistir esta "internalización", dicha resistencia debe ser doblegada, puesto que el consumo productivo de la fuerza de trabajo, la realización de la capacidad para trabajar en trabajo vivo, es su propio presupuesto. Dado que no hay modo de utilizar la fuerza de trabajo más que consumiendo el cuerpo en el que está portada, el de la clase obrera, su suporte material, su lucha tiene que ser vencida para que el capital realice la acción que lo determina. Esto es, debe internalizar el trabajo

25 Bellofiore, Riccardo. "Lost in Translation: Once Again on the Marx-Hegel Connection”. Moseley, Fred y Smith, Tony, eds. Marx's Capital and Hegel's Logic. A Reexamination, Leiden, Brill, 2014, 164-188, p.171. Como vemos, el propio Bellofiore reconoce su deuda con Arthur. Por eso nos detuvimos en la exposición del trabajo de este último en nuestra sección anterior.

26 Vale aclarar que la obra de Colletti recuperada por ciertos miembros de la DS es la que abarca finales de la década del sesenta y el año 1974, en la que en su Entrevista político-filosófica, rompe con el comunismo. En particular, las obras recuperadas son El marxismo y Hegel y La dialéctica de la materia en Hegel y el materialismo dialéctico.

27 Bellofiore, op cit., 2014, 173.

28 Colletti, Lucio. El marxismo y Hegel. México, Grijalbo, 1975, 75.

${ }_{29}$ Bellofiore, Riccardo y Taylor, Nicola. "Marx's Capital I, the Constitution of Capital: General Introduction 1". Bellofiore, Riccardo y Taylor, Nicola, eds. The constitution of capital: essays on volume I of Marx's Capital. Hampshire, Palgrave Macmillan, 2004, 1-34, p. 12.

30 Ibid., 14

31 Bellofiore, op cit., 2014, 183. 
vivo de la fuerza de trabajo como actividad capaz de valorizar el valor ${ }^{32}$. Sin embargo, no es seguro que lo consiga. Escribe Bellofiore:

\begin{abstract}
Marx's capital as self-valorising value is confirmed as akin to Hegel's Absolute Idea, seeking to actualise itself while reproducing its own entire conditions of existence. However, capital's zombielife is dependent on a social condition: capital must win the class-struggle in production, a 'contested terrain': it has to suck away from workers their life, so that it may come back to life as 'undead'. Workers may resist their incorporation as internal moment of capital: this surmountable 'barrier' or 'obstacle' [Schranke] may become an insurmountable 'limit' [Grenze], when conflict becomes antagonism (...) The totality of capital exists only to the extent to which it constitutes a specific social relation of production, which cannot be taken for granted as if it were reproduced mechanically. The social, antagonistic relation of production 'opens' the totality of capital, and to a certain extent 'breaks' it."'33
\end{abstract}

La lucha de clases abre al capital, en el sentido de que el triunfo de éste sobre la clase obrera -su otro interno-, que es su condición de existencia, no puede ser dado por sentado. Más aún, incluso críticamente, Bellofiore señala que Marx desliza la posibilidad de una filosofía de la historia que apunte a la reapropiación de la clase obrera de sus potencias enajenadas en el capital ${ }^{34}$.

Bellofiore dice en la cita que recuperamos que el capital es semejante a la Idea Absoluta por poner sus condiciones de existencia, y este hecho es el que lo convierte en Sujeto: "Marx here gives the positing of the presupposition movement as the ontology of capital as automatic Subject" 35 . Ahora bien, si la lucha de clases abre este movimiento, entonces el capital es sujeto solo en la medida en que el conflicto no devenga antagonismo. Es decir, el capital pone sus propios presupuestos en tanto tenga a la lucha de clases como uno de los momentos de su reproducción, pero esto, según Bellofiore, no puede ser dado por sentado. Con lo cual el capital es sujeto siempre que gane la lucha en el terreno de la producción, internalizando al cuerpo vivo del que puede extraer plusvalor ya que, otra vez, el trabajo debe ser extraído del cuerpo de la clase obrera $^{36}$. Esto porque, nuevamente, el trabajo es tanto del capital -que adquirió el derecho a poner en marcha la fuerza de trabajo al comprarla en el mercado-, como de la clase trabajadora ${ }^{37}$. De ahí la contradicción que atraviesa el capital, según Bellofiore ${ }^{38}$.

Desde nuestra perspectiva, para Bellofiore el capital no es un sujeto, puesto que no puede garantizar que todas sus condiciones de existencia sean puestas por él mismo. Deviene un sujeto al impedir la resistencia abierta de la clase obrera, pero este impedimento puede tornársele absoluto.

La ontología hegeliana, cuyo contenido transpone a la Idea el movimiento propio del capital como sujeto, supone que su movimiento circular está garantizado. De ahí que, por la misma razón que arriba decíamos que el capital, según los propios términos de Bellofiore, no es un sujeto -porque puede no poner todas sus condiciones de existencia-, la ontología de Hegel constituye su apologética, puesto que da por sentado que la lucha de la clase obrera no obstruirá su movimiento subjetivo. En otras palabras, mientras que, según

\footnotetext{
32 Bellofiore, Riccardo, “The Grundrisse after Capital, or How to Re-read Marx Backwards” Bellofiore, Riccardo, Starosta, Guido y Thomas, Peter, eds. In Marx's laboratory: critical interpretations of the Grundrisse. Leiden, Brill, 2013, 17-42, p. 32; Bellofiore, Riccardo y Finelli, Roberto. "Capital, Labour and Time: The Marxian Monetary Labour Theory of Value as a Theory of Exploitation", Bellofiore, Riccardo, ed. Marxian Economics: A Reappraisal Essays on Volume III of Capital. Volume 1: Method, Value and Money. Hampshire, Palgrave Macmillan, 1998, 48-74, p. 51.

33 Bellofiore, op cit., 2014, 183-184.

34 Bellofiore, op cit., 2013, 28.

35 Bellofiore, op cit., 2014, 21. Ver también Bellofiore y Taylor, op cit., 14; Bellofiore y Finelli, op cit., 60.

36 Bellofiore y Taylor, op cit., 185; Bellofiore y Finello, op cit., 60.

37 Bellofiore y Finelli, op cit., 54.

38 Bellofiore, op cit., 2013, 40-41.
} 
Bellofiore, para Marx, el capital necesitaría probarse como sujeto, la dialéctica hegeliana daría por supuesto este carácter ${ }^{39}$.

Vale una aclaración. Hegel ni siquiera se enfrenta al capital como relación social. Cuando decimos que su filosofía, para Bellofiore, constituye la apologética del capital referimos a que refleja su movimiento como si fuese uno circular, no a que le adjudique al capital este movimiento. Es decir, la apologética radica en suponer idealmente que el sujeto del movimiento dialéctico consigue poner sus propios presupuestos, cuando en la realidad el sujeto que es conceptualizado por la dialéctica no lo consigue. A esta adjudicación, decimos, se debe su carácter apologético según Bellofiore.

En resumidas cuentas, o bien:

a) el capital es el sujeto y la dialéctica hegeliana se muestra como la lógica específica del objeto, pero entonces la lucha de clases no resulta una posible barrera a su movimiento, o

b) la lucha de clases puede limitar al capital, pero entonces este no es sujeto y la dialéctica hegeliana da por sentado el círculo bajo el cual el capital pone sus propias condiciones de existencia, cuando en la realidad este círculo debe cerrarse al vencer a la clase obrera.

Entendemos que esta última es la posición de Bellofiore. A partir de ella, encuentra la diferencia específica entre la dialéctica hegeliana y la marxiana a expensas de negarle al capital su condición de sujeto, ya que uno de sus presupuestos puede no ser puesto por él mismo.

Así, queda por elucidar, a nuestro modo de ver, qué toma Marx de Hegel. Es decir, si Hegel representa la apologética del capital por reproducir idealmente el movimiento que pretende tener; si la dialéctica no expresa el movimiento real del capital sino la apariencia de circularidad que pretende levantar, entonces, ¿qué lee Marx en Hegel? ¿Por qué la dialéctica regiría un movimiento que no es circular, sino que está mediado en su apertura por la lucha de clases? La principal dificultad que presenta el planteo de Bellofiore, y que comparte con el de Arthur, es que sostiene que el capital debe certificar su condición de sujeto. Por lo tanto, implícitamente, se le adjudica al trabajo, que es concebido como un otro-interno del capital, la posibilidad de destruirlo a partir de una potencialidad que no está puesta por éste. Lo cual supone enfatizar, a nuestro modo de ver, la exterioridad entre capital y trabajo, toda vez que, aunque se diga que el trabajo es un otro-interno del capital, la destrucción de éste termina dependiendo del primer polo de la duplicidad que presenta el trabajo, como si se tratara de propiedades excluyentes, que se expulsan mutuamente.

Si esto es así, nuevamente, ¿cuál es el "núcleo racional"40 de la dialéctica? ¿En qué aspecto reside su isomorfía con el movimiento real del capital, que no es necesariamente circular? Pasemos entonces a presentar nuestro enfoque, que intenta hacerle justicia a la afirmación de que el capital es el sujeto concreto del modo de producción capitalista y que, a la vez, la dialéctica no es idealista por reflejar adecuadamente este movimiento.

\section{El capital como sujeto y el carácter idealista de la dialéctica hegeliana}

En esta sección, mostraremos en dónde estriba el carácter idealista la dialéctica de Hegel. Para eso, en primer lugar, expondremos cuál es, para nosotros, la clave que hace a la "envoltura mística" que sufre la dialéctica en sus manos. En un segundo momento, mostraremos qué toma Marx de él, para justificar que

39 Bellofiore, op cit., 2014, 183.

40 Vale recuperar el fragmento en el que Marx dice: "La mistificación que sufre la dialéctica en manos de Hegel, en modo alguno obsta para que haya sido él quien, por vez primera, expuso de manera amplia y consciente las formas generales del movimiento de aquélla. En él la dialéctica está puesta al revés. Es necesario darla vuelta, para descubrir así el núcleo racional que se oculta bajo su envoltura mística" Marx, op cit., 1999, 20. 
aquello que Hegel presenta como movimiento del pensamiento se ajusta al devenir del capital como sujeto, esto es, que el carácter idealista no responde a la forma del movimiento dialéctico (al que el capital no respondería necesariamente, según Bellofiore), sino al sujeto al cual Hegel le atribuye este movimiento.

En el modo de producción capitalista, la mercancía es la encargada de asignar las distintas cuotas en las que serán descargados los trabajos útiles concretos necesarios para reproducir la vida social. Dicha organización, entonces, se encuentra portada en la producción de valor, consecuencia de que el conjunto del trabajo necesario para perpetuar la sociedad se realiza bajo la forma de trabajos privados e independientes entre síti $^{4}$. Entonces, la sanción de que un determinado gasto de trabajo abstracto, simple empleo productivo del cuerpo humano ${ }^{42}$, forma parte de aquel socialmente necesario, está puesta en la cambiabilidad del producto de ese trabajo ${ }^{43}$. En otras palabras, solo al encontrar un valor de uso por el cual ser cambiado, el resultado de una cuota de trabajo realizado de forma privada e independiente se consagra como parte del trabajo necesario para producir los valores de uso que la sociedad necesita consumir para reproducirse. Por eso, Marx reitera que la mercancía no manifiesta su valor en su sustancia, sino que lo hace en el cuerpo de otra, comportándose hacia su propia determinación de cambiabilidad al referirse a otra mercancía ${ }^{44}$. Insistimos, la mercancía no tiene valor porque se cambia; se cambia porque tiene valor, y tiene valor porque es el resultado de una asignación indirecta, esto es, privada e independiente, del conjunto de los trabajos útiles concretos que la sociedad necesita realizar para producir los valores de uso que reclama su metabolismo con la naturaleza ${ }^{45}$.

En el despliegue de las determinaciones de la mercancía, el valor que ellas encierran se exterioriza como cosa enfrentada a su valor de uso. Esto es, la cambiabilidad universal pasa a contraponerse al cuerpo de cada una de las mercancías, presentándose de modo exterior a todas ${ }^{46}$. Las mercancías, así, ponen a una de ellas como su contrario, aquella que representa en sí la cambiabilidad universal. El dinero conserva la potencia de disponer del trabajo social bajo cualquiera de sus formas específicas, justamente porque es el representante universal del trabajo social realizado de forma privada e independiente. Las mercancías, así, depositan en una de ellas todos los atributos de los que carecen individualmente ${ }^{47}$.

Con el dinero, la producción de valores de uso manifiesta que se encuentra subordinada a la de valor mismo; a partir de la circulación simple, cuya finalidad es el consumo de una mercancía que se retira del mercado, brota la necesidad de producir valor sí mismo. El valor sustantivado abre entonces el proceso de producción a los fines de acrecentarse, deviniendo capital ${ }^{48}$. El capital consiste en una forma de asignación del trabajo social cuyo objeto no es la producción de valores de uso para la vida humana sino la de producir más de sí como relación social. Se trata de un sujeto que recorre sus formas, las de mercancía y dinero, para volver a sí con una magnitud mayor. Se autovaloriza, vía compra de la fuerza de trabajo y extracción de plusvalía, y en ese movimiento deviene el sujeto de la vida social que organiza ${ }^{49}$.

El sujeto enajenado de la sociedad capitalista aparece en la filosofía de Hegel representado por el pensamiento. Éste, cuyo movimiento se desenvuelve negando cada una de sus determinaciones para afirmarse en ellas, según Hegel se pone en marcha por sí mismo. Esto es, aparece en su filosofía abstraído de

\footnotetext{
${ }^{41}$ Ibid., 52.

42 Ibid., 54.

43 Bellofiore y Talor, op cit., 176.

44 Marx, Karl. Elementos fundamentales para la crítica de la economía politica (Grundrisse) 1857-1858. México, Siglo XXI Editores, 2011, 140.

45 Iñigo Carrera, Juan. El capital: razón histórica, sujeto revolucionario y conciencia, Buenos Aires, Ediciones Cooperativas, $2004,309$.

46 Marx, op cit., 2011, 66.

47 Marx, op cit., 1999, 133-134 y 138.

48 Marx, op cit., 2011, 203.

${ }^{49}$ Marx, op cit., 1999, 188.
} 
toda determinación por el ser social. Ahora bien, esta abstracción del pensamiento de sus determinaciones materiales es resultado de la propia forma enajenada en la que se organiza el trabajo social. Dice Marx:

El hombre extrañado de sí mismo es también el pensador extrañado de su esencia, es decir, de la esencia natural y humana. Sus pensamientos son, por ello, espíritus que viven fuera de la Naturaleza y del hombre. En su Lógica, Hegel ha encerrado juntos todos estos espíritus y ha comprendido a cada uno de ellos, en primer lugar, como negación, es decir, como enajenación del pensar humano, después como negación de la negación, es decir, como superación de esta enajenación, como verdadera exteriorización del pensar humano; pero, presa ella misma aun en el extrañamiento, esta negación de la negación es, en parte, la restauración de estos espíritus en el extrañamiento, en parte la fijación en el último acto, el relacionarse—consigo—-mismos en la enajenación como existencia verdadera de estos espíritus. (Es decir, Hegel coloca en lugar de aquella abstracción fija el acto de la abstracción que gira en torno a sí mismo $(\ldots)) .^{50}$

Nosotros afirmamos, en línea con el argumento de Marx, que Hegel hace girar a la abstracción sobre sí misma puesto que se trata del pensamiento extrañado del ser humano, su sujeto. Ahora bien, Marx indica que este pensamiento extrañado es el de la humanidad extrañada (entfremdete). Esto implica, a nuestro modo de ver, que es la propia enajenación de la humanidad en el producto de su trabajo la que explica el pensamiento extrañado, exterior a ella, puesto por Hegel como su propio motor, como un pensamiento que gira sobre sí mismo y pone las relaciones sociales con las que la humanidad produce su vida. Se trata, para nosotros, del pensamiento puesto en marcha por sí mismo, enajenado, como resultado de la enajenación producida por la organización del trabajo social por el capital.

Así, Hegel toma el devenir autónomo del sujeto de la vida social, el capital, que se pone en marcha a sí mismo con el objeto de producir más de sí, como si fuese la autonomización de la forma humana encargada de organizar dicho trabajo, la conciencia. En vez de ver cómo la necesidad genérica de reproducir la vida a través del trabajo toma la forma de una relación social enajenada, que hace a la conciencia una igualmente enajenada, concibe la autonomización de la relación social como si fuese la autonomización de la conciencia, su puesta en marcha por sí misma. Nuevamente, en tanto la conciencia es la encargada de organizar el trabajo social ${ }^{51}$, la organización autonomizada en el valor que se valoriza se le presenta a esta conciencia, bajo su forma hegeliana, como la autonomización de ella misma de sus determinaciones materiales. Creemos que las siguientes palabras de Marx van en este sentido: "El espíritu filosófico no es a su vez sino el enajenado espíritu del mundo que piensa dentro de su autoenajenación, es decir, que se capta a sí mismo en forma abstracta. La lógica es el dinero del espíritu, el valor pensado; especulativo, del hombre y de la naturaleza; su esencia que se ha hecho totalmente indiferente a toda determinación real y es, por tanto, irreal; es el pensamiento enajenado que por ello hace abstracción de la naturaleza y del hombre real; el pensamiento abstracto".52

La dialéctica de Hegel hace abstracción de las relaciones sociales que la humanidad traba para producir su vida. Este pensamiento abstracto, enajenado, responde, según Marx, a que el propio ser real humano está enajenado. Lo que nosotros sostenemos aquí es que esa abstracción del pensamiento de su sujeto ocurre porque el sujeto de la vida social bajo el modo de producción capitalista es uno autonomizado, es el valor en proceso de valorización. Este sujeto, que es la relación social materializada en el producto del

50 Marx, Karl. Manuscritos Económico Filosóficos. Edición preparada por Juan R. Fajardo para el MIA, 2001. [Consultado el 01 de Junio de 2018] Disponible en: https://www.marxists.org/espanol/m-e/1840s/manuscritos/, 205-206. Vale una aclaración. Las referencias de Marx al trabajo de Hegel son realizadas, mayormente, en cartas, trabajos no publicados por él mismo, anotaciones a textos o como observaciones laterales, a excepción de La sagrada familia (1845) y de Miseria de la filosofía (1847). Utilizaremos los Manuscritos económico-filosóficos y La ideología alemana aunque formen parte de aquellos textos no publicados por el propio Marx (de hecho, ninguno de los dos fue proyectado siquiera como libro por Marx), porque consideramos que, más allá de que la DS se aboque centralmente al trabajo con El Capital, la cuestión general que nos interesa, el vínculo entre Marx y Hegel, permite ser reconstruida a lo largo de toda la producción de Marx.

51 Marx, Karl y Engels, Friedrich. La ideología alemana, Grijalbo, Barcelona, 1970, 26; Iñigo Carrera, op cit., 1-32.

${ }^{52}$ Marx, op cit., 2001, 188. 
trabajo, abre el proceso de producción social con el objeto de producir más de sí. Se trata, entonces, de un proceso automático, que se pone en marcha a sí mismo. Hegel, a nuestro modo de ver, traspone este proceso a la conciencia, como si ésta tuviese la capacidad de poner en marcha su propio movimiento, cuando se trata del atributo humano que organiza la descarga del trabajo social ${ }^{53}$. Entonces, el carácter automático de la relación social enajenada es la que determina el carácter enajenado de la conciencia, presentándosele a Hegel esta forma enajenada como la capacidad del pensamiento de ponerse en marcha a sí mismo. Dice Marx: "El extrañamiento de la conciencia no es considerado como expresión (expresión que se refleja en el saber y el pensar) del extrañamiento real de la humana esencia" 54 .

De este modo, Hegel no se enfrenta a que la conciencia esté enajenada en la relación social vuelta automática. Por el contrario, le adjudica al pensamiento la capacidad de "girar sobre sî", de ponerse en marcha a sí mismo, de ser, a nuestro modo de ver, automático. Esto es, Hegel le adjudica al pensamiento, por desconocer sus determinaciones materiales, el carácter que tiene el capital como sujeto automático de la organización de la vida social. Lo hace porque la propia enajenación de la humanidad determina la aparición de un pensamiento enajenado, el cual, en manos de Hegel, toma la forma de una conciencia abstraída de sus determinaciones materiales. En este carácter extrañado del ser real enajenado reside el aspecto mistificador de la dialéctica hegeliana.

La dialéctica de Hegel pone al pensamiento como el sujeto de la realidad existente y aquel que la determina. Dicho de otro modo, hace del pensamiento el sujeto que se pone a sí mismo en lo otro de él ${ }^{55}$. Hegel, bajo esta forma, reproduce la fetichización de la conciencia en la mercancía, separando a la conciencia de sus atributos reales. Aquí reside, a nuestro modo de ver, el carácter idealista de su filosofía y no, como afirma Bellofiore, en hipostasiar un movimiento que no se ajusta al propio del capital. Desde nuestra perspectiva, el movimiento dialéctico, cuyo sujeto para Hegel es el pensamiento ${ }^{56}$, preside el tránsito del capital como sujeto de la vida social bajo el modo de producción capitalista. Justamente, la potencia de la filosofía hegeliana consiste en haber explicitado las determinaciones generales de este movimiento. Su carácter mistificador, entonces, no estriba en presentar un movimiento al cual el capital no se ajusta en la realidad, sino en abstraer al pensamiento de sus determinaciones materiales, convirtiéndolo en el motor de su despliegue.

Ahora bien, para completar nuestra argumentación, es menester justificar qué creemos que toma Marx de Hegel. Dado que decimos que el capital, por ser el sujeto de la sociedad capitalista, se ajusta al movimiento dialéctico presentado por Hegel, procederemos a mostrar en qué consiste este movimiento y en qué sentido preside el recorrido del valor en proceso de valorización. Para Hegel el principio que explica la organización de toda sociedad es una cierta figura del espíritu que en ella se realiza y que se

\footnotetext{
53 Iñigo Carrera, Juan. "De la crisis al apogeo de la representación: Subjetividad política y acumulación de capital en Argentina", Ciencias Sociales, $N^{0} 79$, Buenos Aires, 2001, 50-56, pp. 51-52.

54 Marx, op cit., 2001, 193.

55 Hegel, George Wilhem. Ciencia de la lógica, Buenos Aires, Ediciones Solar, 1982, TII, 479.

${ }^{56}$ Ibid., 266 y ss.
} 
supera en tanto la conciencia ${ }^{57}$ experimenta la contradicción que le da lugar ${ }^{58}$. En esta experiencia alcanza su propio concepto, que es "la ciencia del saber que se manifiesta" de la conciencia, que se afirma negando sus propias determinaciones. Pero, con esta negación, Hegel no apunta a que la conciencia rechace sus determinaciones en aras de afirmar su independencia. De hecho, rechaza que la libertad de la conciencia dependa de mantener un vínculo exterior con sus propias determinaciones ${ }^{60}$.

Para Hegel, la voluntad no es la actividad de abstraerse de toda determinación, presentándose como pura posibilidad de ponerse frente a lo existente. La voluntad es darse una existencia determinada y, al mismo tiempo, permanecer y reproducirse como voluntad en esta determinación. En eso mismo consiste la libertad: "Pero la verdad de esta universalidad formal, indeterminada por sí, y que encuentra su determinación en aquella materia, es la universalidad que se determina a si misma, la voluntad, la libertad"61. Esto quiere decir que ser libre no implica separarse de las propias determinaciones, abstraerse de ellas como si fuesen límites al albedrío de uno sobre su propia individualidad sino que, por el contrario, supone tenerse a uno por objeto, reconocerse como el límite que la propia voluntad se da a sí misma. Esto es, permanecer idéntico en la separación, afirmarse como uno en la negación de la unidad. En suma, para Hegel la libertad consiste en el reconocimiento de las propias determinaciones. Entonces, no se trata de hacer de la voluntad libre aquello que rechaza de sí las figuras que tome el Yo -según las palabras de Hegel, la voluntad libre tiene necesariamente la forma de un Yo- sino de la existencia de ese Yo en tanto determinado $^{62}$. La conciencia libre es, de este modo, aquella que sabe de sus propias determinaciones, que se sabe determinada y que encuentra su libertad en la determinación, al tomarla por objeto. Así, Hegel desarrolla una forma de conocimiento que no opone como cosas exteriores determinación y libertad ${ }^{63}$. Dice:

Solamente en estos tres momentos se ha cumplido el concepto de la autoconciencia de sí: a) el puro yo no diferenciado de su primer objeto inmediato b) Pero esta inmediatez es ella misma mediación absoluta, sólo es como superación del objeto independiente, o es la apetencia. La satisfacción de la apetencia es, ciertamente, la reflexión de la autoconciencia en sí misma o la certeza que ha devenido verdad. c) Pero la verdad de esta certeza es, más bien la reflexión duplicada, la duplicación de la

\footnotetext{
${ }^{57}$ Utilizamos como sinónimos las palabras conciencia y pensamiento en el contexto de la filosofía hegeliana, cuando expresamente Hegel las discrimina, haciendo de la Conciencia la primera posición del Saber Absoluto en su despliegue (Hegel, George Wilhem. Fenomenología del espiritu, México, Fondo de Cultura Económica, 2006, 51-105) y al Pensamiento una forma de la Autoconciencia (de hecho, un parágrafo de la Fenomenología del Espíritu se denomina "Introducción. La fase de la conciencia a la que aquí se llega: el pensamiento": Hegel, op cit., 2006:121-124). Incluso, la conciencia guarda para sí un conjunto de acápites en la Enciclopedia (Hegel, Hegel, George Wilhem. Enciclopedia de las Ciencias Filosóficas, Alianza, Madrid, 1997, 469-473) y el pensamiento aparece en el Prólogo de la Fenomenología como la unidad mediada de lo que, de modo aconceptual, se presenta como separado: pensamiento y ser (Hegel, op cit., 2006, 36-37). Ahora bien, dice Hegel: “Al principio, la determinabilidad sólo parece serlo por referirse a un otro, y su movimiento parece comunicarse a ella de una fuerza extraña; pero el que tenga en sí misma su ser otro y sea automovimiento es lo que va precisamente implícito en aquella simplicidad del pensamiento, pues ésta es el pensamiento que se mueve y se diferencia a sí mismo, la propia interioridad, el concepto puro (...) La figura concreta, moviéndose a sí misma, se convierte en determinabilidad simple; con ello, se eleva a forma lógica y es en su esencialidad; su ser allí concreto es solamente este movimiento y es un ser allí inmediatamente lógico" (Hegel, op cit., 2006, 38). La conciencia, como punto de partida del movimiento que Hegel acompaña hasta llegar al saber, es ya este movimiento, es esta contradicción que por su propio impulso se enriquece. Por lo cual, es ya pensamiento, es ya, de acuerdo a la cita, concepto puro. La conciencia, en este sentido, se pone en marcha a sí misma y deviene pensamiento. Al tratarlas como equivalentes referimos a que la conciencia es el punto de partida de aquello que va a devenir pensamiento y este movimiento lo realiza por su propio desenvolvimiento, por su propio carácter contradictorio. Así, pretendemos destacar que la conciencia se pone en marcha a sí misma para llegar a ser lo que ya es, cuando si se tomara por objeto el recorrido realizado por Hegel para mostrar este tránsito sería menester detenerse en sus distintas fases. ${ }^{58}$ Hegel, op cit., 2006, 54 y 179.

59 Ibid., 473.

${ }^{60}$ Hegel, George Wilhem. Filosofía del derecho, Buenos Aires, Claridad, 2009, 47-48.

61 Ibid., 55.

62 Ibid., 46.

63 Taylor, Charles. Hegel, México, Antrhopos, 2010, 267.
} 
autoconciencia. Es un objeto para la conciencia, que pone en sí mismo su ser otro o la diferencia como algo nulo, siendo así independiente (...) En cuanto una autoconciencia es el objeto, éste es tanto yo como objeto. ${ }^{64}$

La autoconciencia sintetiza así este movimiento genérico de la conciencia en la cual ella deviene lo que es al negar sus sucesivas figuras. En otras palabras, la autoconciencia muestra cómo la conciencia (como para Hegel cualquier otra cosa), se realiza negando sus propias negaciones, afirmándose en ellas ${ }^{65}$.

Para Hegel, toda determinación traspasa por su propio movimiento a otra, por lo cual el afirmarse mediante la propia negación es propio de todo lo real, sin ser exclusivo del espíritu ${ }^{66}$. Sin embargo, solo con la ciencia del espíritu, forma desplegada del propio espíritu, es decir, con la filosofía de Hegel, el movimiento genérico de afirmación mediante la propia negación se torna consciente ${ }^{67}$.

$\mathrm{Al}$ movimiento que en la ciencia deviene consciente, Hegel lo denomina permanecer en sí en el ser fuera de sí y lo considera la determinación más general de lo real, el corazón del movimiento dialéctico ${ }^{68}$. Aquí reside, a nuestro modo de ver, el "núcleo racional" de su filosofía. Entonces, aquello que Marx rescata de la dialéctica en su forma hegeliana, decimos, es el movimiento de afirmarse a través de la propia negación ${ }^{69}$. Escribe Marx:

Desde el punto de vista del trabajo, su actividad en el proceso de producción se presenta de esta manera: el trabajo aparta de sí mismo su realización en condiciones objetivas, como realidad ajena, y al mismo tiempo y por consiguiente se pone a sí mismo como capacidad de trabajo privada de sustancia, provista meramente de necesidades y enfrentada a ésa su realidad enajenada, que no le pertenece a ella sino a otro; el trabajo no pone a su propia realidad como ser para sí, sino como mero ser para otro, y por tanto también como ser-de-otro-modo, o ser del otro, opuesto a él mismo. Este proceso de realización es a la par el proceso de desrealización del trabajo. El trabajo se pone objetivamente, pero pone esta objetividad como su propio no-ser o como el ser de su no-ser: el capital. ${ }^{70}$

Marx explicita en el mismo sentido que el capital constituye el sujeto de la vida social bajo el modo de producción capitalista porque pone a las mercancías (entre las que se cuenta la fuerza de trabajo) y al dinero, que en la circulación simple aparecen como elementos contrapuestos, como sus propios momentos, esto es, como figuras en las que se conserva para sí mismo. La mercancía y el dinero encierran

${ }^{64}$ Hegel, op cit., 2006, 112-113.

${ }^{65}$ Hegel, op cit., 1982, TI, 193.

${ }^{66}$ Houlgate, Stephen. "G.W.F. Hegel: An Introduction to His Life and Thought". Houlgate, Stephen y Baur, Michael, eds. $A$ Companion to Hegel. Sussex, John Wiley \& Sons, 2011, 1-21, pp. 7-8.

${ }^{67}$ Hegel, op cit., 1997, 602; Hegel, op cit., 2006, 19.

${ }^{68}$ Hegel, op cit., 1982, TI, 135-136 y TII, 72; Hegel, George Wilhem. Diferencia entre el sistema de filosofía de Fichte y el de Schelling, Madrid, Alianza Editorial, 1989, 73.

Hegel hace del movimiento del pensamiento lo propio de todo lo que es, de todo lo real. Por eso se trata de un conocimiento, en esa medida, objetivo, capaz de cuenta de sus determinaciones más abstractas (Hegel, op cit., 1982, TII, 267). Como a Hegel no se le aparece que el ser social determina a la conciencia, no necesita preguntarse qué ser social es el que produce la conciencia dialéctica. Sin embargo, Hegel demuestra la necesidad de que el pensamiento se desarrolle hasta reconocer su propio movimiento dialéctico. Realiza tanto una filosofía de la historia como una historia de la filosofía, en la que se encarga de mostrar el progreso del pensamiento hasta llegar a su propio sistema filosófico, en el que la determinación específica de la Idea se realiza como Espíritu. En este sentido, Hegel desenvuelve la necesidad de cada figura que toma el pensamiento, poniendo esta necesidad en las propias contradicciones en las que ingresa consigo mismo.

Nuestro punto es que por tratar al pensamiento como un sujeto que se pone en marcha a sí mismo, a Hegel no se le presenta la pregunta por su determinación, no se le aparece como cuestión interrogar si hay algo fuera de su propio elemento que lo produce. 69 Marx, op cit., 2001, 186-187; Caligaris, Gastón y Starosta, Guido. 'Which 'Rational Kernel'? Which 'Mystical Shell'? A Contribution to the Debate on the Connection between Hegel's Logic and Marx’s Capital." Moseley, Fred y Smith, Tony, eds. Marx's Capital and Hegel's Logic. A reexamination. Boston, Brill, 2014, 89-111.

${ }^{70}$ Marx, op cit., 2011, 414-415. De hecho, Bellofiore toma a este pasaje como una muestra de la inversión entre sujeto y predicado característica del capitalismo. Bellofiore, op cit., 2013, 27. 
entonces la necesidad de traspasar al otro, anulando su propia autonomía para devenir ropajes de un proceso que mediante ellos se relaciona consigo mismo. Por consiguiente, el capital, en cada una de sus fases, se pone como la verdadera autonomía, como un movimiento que pone sus propios presupuestos y los recorre sin perecer ${ }^{71}$. En esto consiste la dialéctica que lo hace el sujeto de la vida social. Y esta referencia al carácter subjetivo del movimiento es la misma que hace Hegel en el célebre fragmento de la Fenomenología del Espiritu apuntando al devenir de la sustancia en sujeto: "El que lo verdadero sólo es real como sistema o el que la sustancia es esencialmente sujeto se expresa en la representación que enuncia, lo absoluto como espiritu, el concepto más elevado de todos y que pertenece a la época moderna y a su religión. Sólo lo espiritual es lo real; es la esencia o el ser en sí, lo que se mantiene y lo determinado -el ser otro y el serpara sí- y lo que permanece en sí mismo en esta determinabilidad o en su ser fuera de sí o es en y para sì? ${ }^{\prime}$.

Esto es, tanto para Marx como para Hegel el sujeto del movimiento dialéctico es aquel que se mantiene en sí mismo al poner las formas que recorre -el capital en el caso de Marx, el espíritu absoluto en el caso de la fenomenología hegeliana. Se trata entonces de las determinaciones generales de la dialéctica, que indican que cada momento traspasa a otro por su propia contradicción inmanente. Frente a la tesis de Bellofiore, aquí reside aquello que Marx toma de Hegel, lo cual explica por qué toma al capital como el sujeto de la vida social bajo el modo de producción capitalista.

\section{Conclusiones}

El presente escrito tomó por objeto la lectura que realiza Riccardo Bellofiore, inscripto en la DS, del vínculo entre Marx y Hegel. Nos detuvimos en el trabajo de Bellofiore porque su línea de investigación representa una de las tendencias más extendidas dentro de las perspectivas sobre el tema. Esta línea, cuyo aporte fundamental fue la producción de Lucio Colletti, sostiene que el carácter idealista de la dialéctica hegeliana responde a que expresa idealmente el movimiento real del capital como relación social enajenada. Empero, en esta expresión, según Bellofiore Hegel le atribuye a la dialéctica de lo absoluto una circularidad de la que el capital carece. Pues para Bellofiore el capital no alcanza el estatuto de sujeto de forma necesaria, ya que en su transcurso debe doblegar la resistencia de la clase obrera, un sujeto-otro capaz de frenar el devenir del capital como relación social que pone sus propios presupuestos. Así, la dialéctica hegeliana postularía un sujeto plenamente circular y autofundado, mientras que el capital debería triunfar en su lucha contra la clase trabajadora para alcanzar esta condición. El idealismo de Hegel residiría, justamente, en ser la lógica pecular del objeto peculiar que representa el capital, pero transponiendo el movimiento de este objeto como si necesariamente fuese capaz de poner sus propios presupuestos.

Nuestra principal objeción al razonamiento de Bellofiore ha sido que en su argumento la filosofía de Hegel carga con un talante idealista porque el capital no constituye el sujeto de la producción y el consumo sociales. Pues si el capital consiguiese poner todos sus presupuestos, entonces sería un sujeto autofundado tal y como el absoluto hegeliano. En otras palabras, si el capital pudiera poner necesariamente a la lucha de clases como uno de sus momentos, entonces, en línea con el argumento de Arthur, Bellofiore tendría que aceptar que la dialéctica hegeliana de lo absoluto rige igualmente al movimiento del capital como sujeto.

Frente a la propuesta de Bellofiore, nuestra tesis es que el capital es el sujeto pleno de la vida social bajo el modo de producción capitalista, no obstante lo cual la dialéctica hegeliana encierra un carácter idealista. Esto se debe a que el talante idealista responde a que Hegel hace al pensamiento el sujeto de su propio despliegue, autonomizándolo de las determinaciones materiales que lo explican. Lo cual, a nuestro modo

71 Marx, op cit., 2011, 194, 201-203 y 273-274.

${ }^{72}$ Hegel, op cit., 2006, 19. 
de ver, es resultado de que el capital como relación social general es el sujeto autonomizado de la vida social. Es decir, nuestra hipótesis es que Hegel se representa la autonomización del capital como sujeto, el hecho de recorrer sus figuras negándolas para afirmarse en ellas, como si ésta fuese la del pensamiento respecto de sus determinaciones sociales. Hegel, entonces, transpone a la relación social objetivada en el producto del trabajo, que se mueve para producir más de sí, al terreno del pensamiento, atribuyéndole a la conciencia aquello que detenta el capital. Por consiguiente, Hegel describe objetivamente las determinaciones generales del movimiento dialéctico, que se resumen cuando Marx indica que:

Hegel ha concebido la negación de la negación, de acuerdo con el aspecto positivo en ella implícito, como lo verdadero y único positivo $\mathrm{y}$, de acuerdo con el aspecto negativo también implícito, como el único acto verdadero y acto de autoafirmación de todo ser, sólo ha encontrado la expresión abstracta, lógica, especulativa para el movimiento de la Historia, que no es aún historia real del hombre como sujeto presupuesto, sino sólo acto genérico del hombre, historia del nacimiento del hombre. ${ }^{73}$

El núcleo racional de la dialéctica hegeliana estriba en haber desarrollado las formas generales de este movimiento, cuya piedra fundamental es la negación de la negación. Bellofiore separa la unidad entre las formas subjetivas y objetivas que toma el ser social. Lo hace al atribuirle a la clase trabajadora la posibilidad de interrumpir el devenir del capital a partir de una potencia que le es parcialmente exterior a este último Por insistir en la unidad de las formas de objetividad y subjetividad que toma el ser social, el conocimiento dialéctico se determinada como la organización consciente de la práctica humana bajo el modo de producción capitalista y, por consiguiente, como la ciencia revolucionaria de la clase obrera. Ciencia que lleva implícita el conocimiento consciente de sus propias determinaciones, que toma al conocimiento como una forma de la práctica transformadora; ni como una parte, ni como una acción que se relaciona con ella desde fuera.

El conocimiento dialéctico, como crítica práctica, rechaza plantearse que ciertas condiciones materiales lo limitan o potencian exteriormente. Al penetrar las formas aparenciales que toma su propia acción transformadora, se coloca en el interior de ésta, como una de sus potencias. Por ello, en la crítica a toda perspectiva que se plantee la exterioridad entre conocimiento y acción, el terreno de la materialidad de la práctica humana concreta nunca se abandona.

\section{Bibliografía}

Albritton, Robert y Simoulidis, John, eds. New Dialectics and Political Economy. Basingstoke, Palgrave Macmillan, 2003.

Arthur, Cristopher. "Hegel's Logic and Marx's Capital", Moseley, Fred, ed. Marx's method in Capital. New Jersey, Humanities Press, 1993, 63-87.

Arthur, Christopher. The New Dialectic and Marx's 'Capital', Leiden, Brill, 2004.

Arthur, Christopher. "De la crítica de Hegel a la crítica de capital". Robles Báez, Mario, comp. Dialéctica y Capital. Elementos para una reconstrucción de la crítica de la economía política, México, Universidad Autónoma Metropolitana, 2005, 229-256.

Bellofiore, Riccardo y Finelli, Roberto. "Capital, Labour and Time: The Marxian Monetary Labour Theory of Value as a Theory of Exploitation”, Bellofiore, Riccardo, ed. Marxian Economics: A Reappraisal

${ }^{73}$ Marx, op cit., 2001, 186-187. 
Essays on Volume III of Capital. Volume 1: Method, Value and Money. Hampshire, Palgrave Macmillan, 1998, 48-74.

Bellofiore, Riccardo y Taylor, Nicola. "Marx's Capital I, the Constitution of Capital: General Introduction 1". Bellofiore, Riccardo y Taylor, Nicola, eds. The constitution of capital: essays on volume I of Marx's Capital. Hampshire, Palgrave Macmillan, 2004, 1-34.

Bellofiore, Riccardo, "The Grundrisse after Capital, or How to Re-read Marx Backwards" Bellofiore, Riccardo, Starosta, Guido y Thomas, Peter, eds. In Marx's laboratory: critical interpretations of the Grundrisse. Leiden, Brill, 2013, 17-42.

Bellofiore, Riccardo. "Lost in Translation: Once Again on the Marx-Hegel Connection”. Moseley, Fred y Smith, Tony, eds. Marx's Capital and Hegel's Logic. A Reexamination, Leiden, Brill, 2014, 164-188.

Caligaris, Gastón y Starosta, Guido. "Which 'Rational Kernel'? Which 'Mystical Shell'? A Contribution to the Debate on the Connection between Hegel's Logic and Marx’s Capital." Moseley, Fred y Smith, Tony, eds. Marx's Capital and Hegel's Logic. A reexamination. Boston, Brill, 2014, 89-111.

Colletti, Lucio. El marxismo y Hegel. México, Grijalbo, 1975.

Hegel, George Wilhem. Ciencia de la lógica, Buenos Aires, Ediciones Solar, 1982.

Hegel, George Wilhem. Diferencia entre el sistema de filosofía de Fichte y el de Schelling, Madrid, Alianza Editorial, 1989.

Hegel, George Wilhem. Enciclopedia de las Ciencias Filosóficas, Alianza, Madrid, 1997

Hegel, George Wilhem. Fenomenología del espiritu, México, Fondo de Cultura Económica, 2006.

Hegel, George Wilhem. Filosofía del derecho, Buenos Aires, Claridad, 2009.

Houlgate, Stephen. “G.W.F. Hegel: An Introduction to His Life and Thought”. Houlgate, Stephen y Baur, Michael, eds. A Companion to Hegel. Sussex, John Wiley \& Sons, 2011, 1-21.

Iñigo Carrera, Juan. El capital: razón histórica, sujeto revolucionario y conciencia, Buenos Aires, Ediciones Cooperativas, 2004.

Iñigo Carrera, Juan. "De la crisis al apogeo de la representación: Subjetividad política y acumulación de capital en Argentina", Ciencias Sociales, Nº 79, Buenos Aires, 2001, 50-56.

Marx, Karl. El capital, Tomo I, vol. 1, México, Siglo XXI Editores, 1999.

Marx, Karl. Manuscritos Económico Filosóficos. Edición preparada por Juan R. Fajardo para el MIA, 2001. [Consultado el 01 de Junio de 2018] Disponible en: https://www.marxists.org/espanol/me/1840s/manuscritos/

Marx, Karl. Elementos fundamentales para la crítica de la economía política (Grundrisse) 1857-1858. México, Siglo XXI Editores, 2011.

Marx, Karl y Engels, Friedrich. La ideología alemana, Grijalbo, Barcelona, 1970.

Moseley, Fred y Cambell, Martha, eds. New Investigations of Marx's Method. New Jersey, Humanities Press International, 1997. 
Moseley, Fred y Smith, Tony, eds. Marx's Capital and Hegel's Logic. A Reexamination. Leiden, Brill, 2014.

Murray, Patrick. Marx's Theory of Scientific Knowledge. New York, Humanity Books, 1990.

Murray, Patrick. "La necesidad del dinero: cómo Hegel ayudó a Marx a superar la teoría del valor de Ricardo". Robles Báez, Mario, comp. Dialéctica y Capital. Elementos para una reconstrucción de la crítica de la economía política, México, Universidad Autónoma Metropolitana Báez, 2005, 37-62.

Robles Báez, Mario. Dialéctica y Capital. Elementos para una reconstrucción de la crítica de la economía política. México, Universidad Autónoma Metropolitana, 2005.

Sekine, Thomas. "The Dialectic, or Logic that Coincides with Economics". Albritton, Robert y Simoulidis, John, eds. New Dialectics and Political Economy. Hampshire, Palgrave Macmillan, 2003, 120-130.

Smith, Tony. The Logic of Marx's Capital. Replies to hegelian criticisms, Albany, SUNY press, 1990.

Smith, Tony. Dialectical Social Theory and Its Critics. From Hegel to Analytical Marxism and Postmodernism. Albany, New York, State University of New York Press, 1993.

Starosta, Guido. "Fetichismo y revolución en la teoría marxista contemporánea: una evaluación crítica de la Neue Marx-Lektüre y el Marxismo Abierto en clave metodológica", Izquierdas, 37 (diciembre), 2017, 162190.

Taylor, Charles. Hegel, México, Antrhopos, 2010. 